\title{
A Preliminary Analysis of the Perception Gap between Employers and Vocational Students for Career Sustainability
}

\author{
Ali Rizwan ${ }^{1, *(\mathbb{D})}$, Suhail H. Serbaya ${ }^{1} \mathbb{D}$, Muhammad Saleem $^{2} \mathbb{D}$, Hemaid Alsulami ${ }^{1}$, Dimitrios A. Karras ${ }^{3}$ \\ and Zobia Alamgir 4
}

check for updates

Citation: Rizwan, A.; Serbaya, S.H.; Saleem, M.; Alsulami, H.; Karras, D.A.; Alamgir, Z. A Preliminary Analysis of the Perception Gap between Employers and Vocational Students for Career Sustainability. Sustainability 2021, 13, 11327. https:/ / doi.org/10.3390/su132011327

Academic Editors: Ilaria Di Maggio and Sara Santilli

Received: 6 September 2021

Accepted: 11 October 2021

Published: 13 October 2021

Publisher's Note: MDPI stays neutral with regard to jurisdictional claims in published maps and institutional affiliations.

Copyright: (c) 2021 by the authors. Licensee MDPI, Basel, Switzerland. This article is an open access article distributed under the terms and conditions of the Creative Commons Attribution (CC BY) license (https:/ / creativecommons.org/licenses/by/ $4.0 /)$.
1 Department of Industrial Engineering, Faculty of Engineering, King Abdulaziz University, Jeddah 21589, Saudi Arabia; sserbaya@kau.edu.sa (S.H.S.); healsulami@kau.edu.sa (H.A.)

2 Department of Industrial Engineering, Faculty of Engineering-Rabigh, King Abdulaziz University, Jeddah 21589, Saudi Arabia; msaleim1@kau.edu.sa

3 School of Science, National and Kapodistrian, University of Athens (NKUA), 34400 Athens, Greece; dakarras@uoa.gr

4 Department of Research and Analysis, Knowledge Kottage, Islamabad 44000, Pakistan; zoobiaalamgir@gmail.com

* Correspondence: arkhan71@kau.edu.sa

\begin{abstract}
Background: Nowadays, technological advancement plays a key role in the economic uplift of developing countries, and it is paramount that the youth of these countries are wellequipped with both vocational and technical skills to bring about sustainability in their careers. (2) Methods: The present study aims to investigate the perception gap between vocational students and industrial employers with regard to employability skills. In this regard, data were collected from 683 vocational students from urban/rural areas studying in the public/private vocational institutions of a developing country. Similarly, 82 vocational employers were contacted about their perception of employability skills. A questionnaire comprising 20 questions was administered online to both students and employers for registering their responses. Data were analyzed with the help of descriptive statistics, interval plots, and an Ishikawa diagram. (3) Results: The findings reveal that vocational employers give maximum importance to interpersonal, technical, and entrepreneurial skills, while students perceive that their technical and computing skills are vital for sustainable careers. Similarly, the rural/public students showed minimum levels of competency in these skills as compared with their counterparts living in rural areas and studying in the private institutions. Furthermore, structured interviews were conducted with the concerned stakeholders to develop a remedial framework for the sustainable careers of these vocational students. (4) Conclusions: The results of the study not only bring sustainability to the vocational sector of developing countries, but to all those countries enjoying similar socioeconomic backgrounds.
\end{abstract}

Keywords: vocational education; sustainable future; career development; technical skills

\section{Introduction}

In the dynamic environment of the 21st century, technological advancements have played a key role in the economic uplift and sustainable development of both developed and developing countries [1]. Sustainability, on the other hand, cannot be achieved without the active involvement of key stakeholders, including quality human resources, which play a decisive role in the economic development of their respective societies [2]. Since the recognition that the skills and knowledge possessed by human resources are crucial to the delivery of quality products and services [3], most countries are moving towards knowledge economies by linking their education systems with entrepreneurial and vocational training in order to reduce unemployment and poverty among the populaces [4].

It is the key responsibility of the education system to prepare youth for sustainable career domains, and it is also education that provides sustainable opportunities for future 
growth [5]. The current suggested mechanism of vocational education is to help the youth in their career domains by providing an initial step from education to career. Furthermore, this mechanism helps young people to find sustainable careers faster than any other educational domains because of the occupation of specific skills; these industrial skills make them valuable for that specific role. As this mechanism has a positive impact on life courses as well, this indicates the significance of occupational skills in life as compared to general educational domains. Thus, vocational institutes work by keeping in mind the job market needs and by producing occupationally skilled people through hands-on learning.

Virtually all research in the field of education and comparative stratification are classified into two major categories: vocational education and general education. It is evident from previous research that the dichotomous classification of educational programs is based on vocational skills and general skills.

\section{Literature Review}

\subsection{Vocational Education and Training}

Vocational education and training (VET), which is considered a primary strength for bringing about the sustainability of these programs, is generally referred to as skilloriented education, in which students are prepared for different trades with the help of hands-on job-specific instructions and occupational experience [5]. By doing so, not only is the employability time of the students reduced, but their transformation into a vibrant and skillful workforce also takes place, which strengthens their career path [6]. In this pursuit, we must ensure that the programs are technology-driven and well-aligned with the requirements of the labor market; this will be helpful in exploring the understanding of people and markets with regard to sustainable career growth [7]. On the other hand, a critical challenge is anticipated: any disparity between the curriculum and the market needs not only increases the employability time of students, but also makes them vulnerable to stress, anxiety, and depression [8]. These views are further supported by Ali et al. in their study conducted on 812 vocational students and 129 industrial employers in Pakistan, in which students perceived that their technical skills played an important role in procuring them jobs, while employers placed more importance on their creativity, as well as interpersonal and other soft skills [9]. A similar study in China indicates a gross mismatch between market requirements and the competencies possessed by graduating vocational students [10].

\subsection{Contemporary Reforms in Vocational Education}

Because of the inadequacy of these programs to address the needs of the labor market, an extensive overhauling and consensus-based reforms are required to improve the quality of these programs for practical sustainable development [11]. In their research, Noor et al. surveyed 453 vocational students in Malaysia and suggest that problem-based and experiential forms of learning play dominant roles in improving student performance, as opposed to conventional theoretical approaches, strengthening career sustainability as well as the self-confidence of the students [12]. Another study, conducted by Alecxandrina et al. in Romania, proposes that the balance between information and communication technology (ICT) is pivotal in developing the necessary skills and competencies among vocational students in order to provide continuous development [13]. Moreover, in addition to institutional knowledge, early exposure to industrial processes also generates extra impetus among vocational students and guides them towards sustainable careers, social equity, and economic development [14]. Similarly, the engagement of industrial experts with vocational students as mentors helps in creating awareness among them about realworld problems, in addition to the evaluation of their employability skills before joining formal employment [15]. Moreover, collaborative learning between industry experts and course teachers also contributes to increasing student satisfaction by providing a friendly environmental energy towards meeting the goals of a sustainable future [16]. Meanwhile, Thomas Bolli introduced the concept of education-employment linkage (EEL) 
and highlights the role of vocational employers in defining quality standards, curriculum design, and classroom education to support sustainability targets [17].

\subsection{Contextual Modularisation of Vocational Education}

However, the structure of vocational education experiences varies a lot owing to the diversified requirements of different countries, the individual and social behaviors of vocational students, and industry authorities [18]. For instance, Switzerland focuses on the combination of school and workplace learning; Singapore engages vocational employers to strengthen their vocational schools; Dutch vocational education registers almost two-thirds of their high school students in various technical and vocational programs; Denmark introduced hundreds of vocational programs to enrich their vocational education; while Korea and Hong Kong emphasize enrolling five and seven percent of their youth in vocational education programs, respectively [19]. Similarly, in a developing country such as Pakistan, most of the urban area parents/guardians still perceive vocational education as totally worthless and prefer to put their children in alternate fields of higher education [20]. In this regard, Amin et al. put forward a synthesized approach that highlights the role of educational leaders as pivotal in convincing parents to register their children for these programs from several perspectives [21]. Although the government of Pakistan has set up the National Vocational and Technical Training Commission (NAVTTC) at the federal level, and Technical Education and Vocation Training Authorities (TEVTAs) at the provincial levels, they are still unable to fill the supply/demand gap of the skilled workforce [22]. Nevertheless, both public and private sector polytechnic institutes also offer various kinds of VET programs. However, a major portion of technical training is done through an informal system in which a skilled person transfers his/her skill to an apprentice [23]. Nevertheless, the number of students enrolled in VET programs in Pakistan is increasing. However, because these programs are not relevant to local industry, the graduates face great difficulties in finding timely jobs [24]. As a result, most of the vocational graduates remain unemployed for longer periods of time, not only impacting their health, but also shattering the confidence level of parents/guardians in these training programs [25].

\subsection{Theoretical Models in Adult Learning}

Numerous studies have been consulted to explore the theoretical models that are linked to the sustainability and career adaptability of youth. In the transformative learning theory (TLT) of Mezirow [26], transformation through different variations is been discussed in relation to adult education. The implementation of transformative learning theory in vocational education is paramount because of the expansion of one's consciousness that ultimately brings clarity of purpose to learners. However, Schnep et al. emphasize the importance of personal and sociocultural contexts and propose adding the element of context as a fourth foundation in the transformative learning theory [27]. Similarly, the Crites' model of career and vocational development [28] is widely implemented and applied in the current research to suggest the best possible strategies for the guidance of vocational employers and technical institutions. The vocational development inventory by Crites helps students to make appropriate vocational plans, and research conducted by Ertelt et al. further highlights the holistic role of apprenticeships for sustainable career development [29]. Furthermore, York's USEM employment capability structure model [30] not only guides vocational students in self-assessing their employability skills, but also helps them in organizing the complexities of career development. The determinants of the USEM model are further validated by Bennet and Ananthram, with the help of the multifactor perceived employability scale, in which the self-efficacy of students is used to determine their metacognition and learning responses. In this way, the aforementioned models are used to integrate the skills learnt at vocational institutions along with the needed skills that count for their sustainable future.

As is evident from the literature, various studies have been performed in order to observe the effectiveness of these programs; however, most of these studies are context- 
specific and were carried out with regard to the general efficacy of these programs. It is evident that a strong connection between the students' employability (SE) and employers not only reduces stress among students, but also minimizes the chances of them taking risks in the selection of their careers [31,32]. Thus, the present study aims to observe the perception gap, with regard to employability skills, between vocational students and industrial employers in the context of a developing country, where a major portion of the population is still living in rural areas and any delay in their employment not only creates stress and anxiety among them, but also undermines the credibility of these vocational institutions as well. Current research primarily focuses on heightening the creditability of vocational institutions in rural, as well as urban, areas, where the main focus is to uplift the employability rate. Therefore, this study explores whether any gap exists between the perception of employers and vocational students, rather than looks at the impact of living in urban/rural areas and studying in public/private institutions. This recent study focuses on the life course imprints of vocational education on employment, arguing that there is a vocational decline and that having occupation-specific skills is a benefit at the start of a career.

\subsection{Research Hypotheses}

The three following research hypotheses were developed for further analysis. For this purpose, the determinants were taken from the appropriate theoretical models: the transformative learning theory (TLT) of Mezirow [33]; Crites' model of vocational adjustment [28]; and York's USEM employment capability structure model [30] in order to validate the research hypotheses. However, it is vital to understand the difference between general and specific skills, introduced by Becker in human capital theory [34]. Specific skills have direct connection and validity within specific occupational domains, whereas general skills can be applied in a variety of contexts. Later on, Shavit and Miller classified the domains into specific vocational skills and general skills [35]. The questionnaire of this study is based on the above theoretical models.

Moreover, the present study's research hypotheses are based on the theory and notion of the perception gap. The concept of employability skills used in the literature is a construct that "grows by accretion with the addition of new sub-constructs", argues Smith et al. [36]. Since no single party, out of the ones identified in the literature review, and especially the three above-stated theoretical models, has control over this construct, it is subject to different interpretations from those involved in the aforementioned processes, including, namely, education system policymakers, employers, trainers, and students. As definitions of employability have grown in recent years, many studies have investigated reasons for the disproportions between the objectives of the education system and the requirements of employers. Leveson [37] suggests that the problem could be one of perception, specifically, differences in the understanding of the language that underlies the whole employability theoretical structure. A lack of understanding between the interested bodies may lead to potential discrepancies in the aims of competency-based vocational education. Sin and Neave [38] claim that, "as a concept, employability commands little consensus. Rather it is interpreted in the light of each interest group's concerns as a floating signifier". It is, therefore, exactly this development, with employability skills being a fluctuating signifier among the interested parties identified in the above-stated theoretical models, that inspires the herein settled main research questions:

- What are vocational employers' and students' perceptions of desirable employability skills, and how do they converge or diverge?

- What are the perception gaps of rural/urban areas and public/private institutions regarding desirable employability skills?

Of course, there are many other hypotheses that could be investigated in the context of vocational training because of the combination of the many interested and involved bodies. However, the present study has focused on the above main research questions, analyzing the situation in developing countries. 
However, one critical question is herein raised on why the present study and its hypotheses are important in the field. The reason for conducting such studies with regard to identifying the possible perception gaps between employability skills is because convergence is needed in the perception of all interested parties if sustainability is the goal in vocational training. In order to achieve such convergence, a subsequent leapfrog step should be followed, namely, the definition of suitable strategies for closing the gaps between the perceptions and interpretations of the different involved bodies. The properness of such strategies can be measured by the relevant gaps. The contribution of the present study lies in the identification and measurement of such perception gaps between the involved parties based on the factors defined in the three previously mentioned theoretical models, namely, the transformative learning theory (TLT) of Mezirow [33], Crites' model of vocational adjustment [28], and York's USEM employment capability structure model [30]. The authors aim at presenting, in the near future, a sequel of this work measuring the impact of suitable strategies, such as the ones defined in Section 5 herein, in the convergence of the perceptions of the different interested bodies regarding vocational-training-based employability skills.

On the basis of the above-mentioned theories and analysis, the following three hypotheses were developed to explore the impact of the perception gap between industrial employers and vocational students. The hypotheses formulated assume the connectivity between the occupational-specific education system and current job/industry demands, so as to define the mechanism of vocational institutions in work transition.

Hypotheses 1 (H1). A significant perception gap exists between vocational employers and vocational students with regard to employability skills.

Hypotheses 2 (H2). Living in urban vs. rural areas creates significant differences with regard to the perception of employability skills.

Hypotheses 3 (H3). Studying in public/ private vocational institutions creates a significant difference in the competency levels of employability skills.

\section{Materials and Methods}

\subsection{Participants}

The participants of the study were vocational students and vocational employers. The students were later categorized into four clusters for further analysis: urban/public, urban/private, rural/public, and rural/private. Table 1 depicts the demographic details of the surveyed population, vocational students, and vocational employers.

Table 1. Demographic profile of the participating students and vocational employers.

\begin{tabular}{cccc}
\hline Demography & $\begin{array}{c}\text { Frequency in the } \\
\text { Sample }\end{array}$ & Percentage (\%) & $\begin{array}{c}\text { Cumulative } \\
\text { Percentage (\%) }\end{array}$ \\
\hline Urban-private & 175 & 22.9 & 22.9 \\
Urban-public & 189 & 24.7 & 47.6 \\
Rural-private & 141 & 18.4 & 66 \\
Rural-public & 178 & 23.3 & 89.3 \\
Employers & 82 & 10.7 & 100 \\
Total & 765 & 100 & \\
\hline
\end{tabular}

\subsection{Materials/Measures}

The theoretical framework for the study was built on the reflective judgement and cosmological concept of adult learning presented in the transformative learning theory (TLT) of Mezirow [33], the determinants of the Crites' model of vocational adjustment, highlighting the responses of an individual to choose and develop a career [28], and York's USEM employment capability structure model, in which students perceive and self-assess their employability skills with the help of the didactic-pedagogical [30]. Furthermore, the 
determinants of the questionnaire were taken from the previous research of Van et al. [39], and Paadi [40], which were later grouped into ten categories: computing skills, virtual skills, cognitive skills, social skills, emotional intelligence, technical skills, resource handling skills, interpersonal skills, effective communication, and entrepreneurial skills.

Moreover, the determinants of the proposed framework for the four clusters of ru$\mathrm{ral} / \mathrm{public}$, rural/private, urban/public and urban/private vocational students were developed with the help of brainstorming sessions and structured interviews that were conducted with the concerned stakeholders. The results of the questionnaire were analyzed by looking at the mean value of each group. Later on, hierarchical analysis and an interval plot were used to further investigate the root causes, which are augmented with an Ishikawa diagram, to identify the causes and effects of student skills and competencies.

\subsection{Procedure}

To this end, data were collected through an online survey method because of its wide coverage and cost-effectiveness. The same questionnaire was administered to both vocational students and vocational employers and was comprised of twenty questions. These questions were mainly categorized into ten categories: entrepreneurial skills, effective communication, interpersonal skills, resource handling skills, technical skills, emotional intelligence, social skills, cognitive skills, virtual skills, and computing skills. In the process, 683 vocational students and 82 vocational employers responded positively. The responses of the students and employers were collected on a five-point Likert-type scale, ranging from 1 (highly dissatisfied) to 5 (highly satisfied). In the first part of the questionnaire, vocational students were asked to rate these skills according to their perceived importance. In the second part of the questionnaire, they were asked to rate each skill according to their perceived competency level in each skill.

Similarly, the responses of the vocational employers were collected from the same questionnaire. However, they were only asked to rate these skills according to their perceived importance on a five-point Likert-type scale. Furthermore, reliability and validity tests were conducted to assess the authenticity of the collected data. Table 2 depicts the reliability of the data as the values of Cronbach's alpha $(\alpha)$ are greater than 7, which indicates that the data is valid for further analysis. Similarly, the values in the KMO analysis (Kaiser-Meyer-Olkin) are $>0.5$, which shows the internal consistency of the data, while the $<0.05$ values in Bartlett's test depict the suitability and compactness of the data.

Table 2. Reliability and validity tests of students' and employers' perceived importance.

\begin{tabular}{ccccc}
\hline Demography & Questions & $\begin{array}{c}\text { Cronbach's } \\
\text { Co-Efficient }(\boldsymbol{\alpha})\end{array}$ & KMO & Bartlett's Test \\
\hline Urban/private & 20 & 0.81 & 0.57 & 0.003 \\
Urban/public & 20 & 0.71 & 0.49 & 0.017 \\
Rural/private & 20 & 0.79 & 0.64 & 0.001 \\
Rural/public & 20 & 0.67 & 0.46 & 0.019 \\
Vocational Employers & 20 & 0.73 & 0.39 & 0.021 \\
\hline
\end{tabular}

\subsection{Data Analysis}

Having found the suitability of data after checking its reliability and validity, bar graphs were used to assess the perceived importance and competency levels of vocational students in employability skills. The mean values of students living in urban/rural areas and studying in public/private universities are plotted against each other for comparative analysis. Similarly, the mean values of each skill are computed through bar graphs in order to find out their central tendency. Afterwards, a descriptive analysis, comprised of mean and standard deviation, were used to check the perceived importance of vocational employers with regard to employability skills, which was then compared with the perception levels of students regarding these skills. Later on, the hierarchical analysis was performed to assess the skill levels of students in each of the four clusters of urban/private, 
urban/public, rural/private, and rural/public. An interval plot was used to compare the mean competency levels of the students in the four vocational groups. Subsequently, a cause-and-effect analysis of the vocational students' perception and their competency levels for sustainable career adaptability was conducted with the help of the Ishikawa diagram. Structured interviews were then conducted with the relevant stakeholders in order to figure out remedial solutions. Finally, a remedial framework is suggested, along with the actions and list of sponsors needed in order to reduce the perception gap and bring sustainability to the careers of vocational students.

\section{Results}

\subsection{Significance and Competency Level of Urban/Private Students}

Under the umbrella of transformative learning theory (TLT), it is vital to look for the mean of each cluster's competency in each skill in order to find out the determinants that cause the perception gap between urban/private students. Figure 1 indicates vocational students' perceived importance of and competency level in each skill. The results indicate that vocational students living in urban vicinities and studying in private vocational institutions placed maximum importance on resource-handling skills and technical skills, while less importance was given to cognitive and interpersonal skills. On the other hand, while rating their competency levels for the aforementioned skills, they expressed high levels of competency in technical skills and resource-handling skills, while expressing low levels of competency in their communication and virtual skills. The results are in accordance with the findings of a study carried out in the Malaysian industrial sector, where vocational students also expressed a lack of satisfaction towards their communication and social skills [41], and the urban/private cluster mean value also indicates low levels of competency in communication skills along with virtual skills.

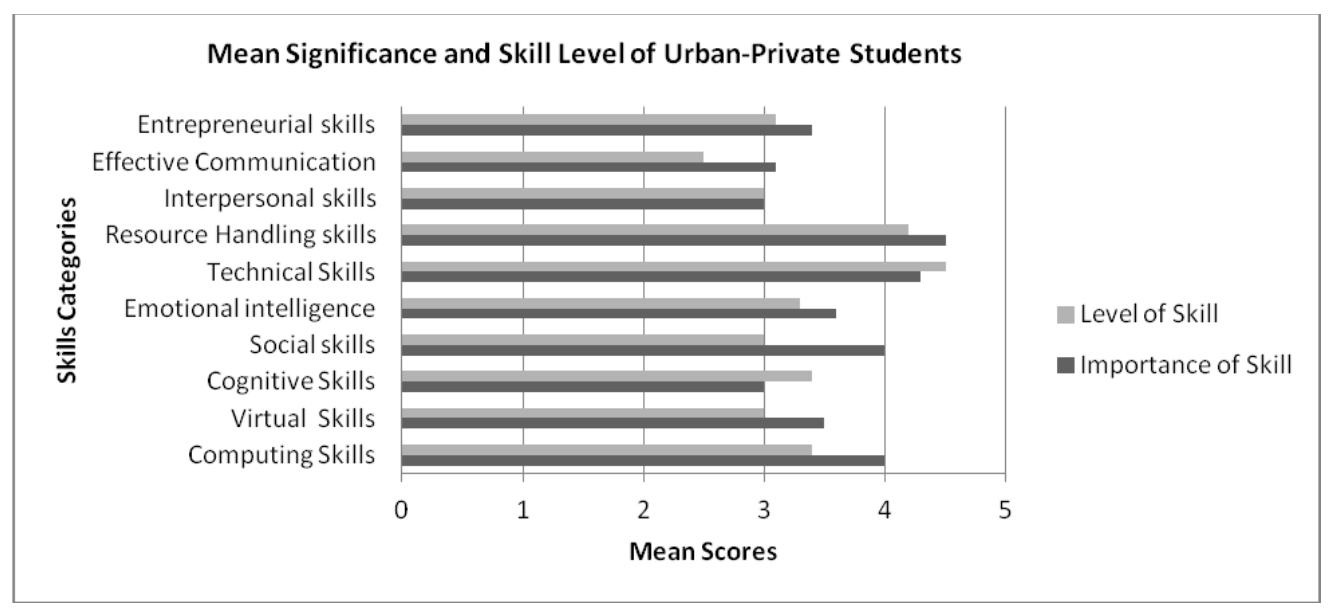

Figure 1. Mean scores of urban/private vocational students' perception.

\subsection{Significance and Competency Level of Urban/Public Vocational Students}

Figure 2 shows the mean values of the perceived importance and competency levels of those students who live in urban vicinities and study in the public vocational institutes. The results indicate that, according to students' perception, their computing and resourcehandling skills are the most important skills for procuring jobs. However, at the same time, they do not rate themselves as very good in these skills. On the other hand, they consider that their social and entrepreneurial skills have minimul roles in procuring them early employment. However, despite this fact, they rate their competency levels in these skills as very good. The findings share a common similarity with the research of Zaharim et al., in which the students felt confident about their resource-management competencies and underscored the importance of these skills for a secure and sustainable future [42]. 
The mean value of each skill also highlights the hindrances of vocational urban/public students in procuring an established career path.

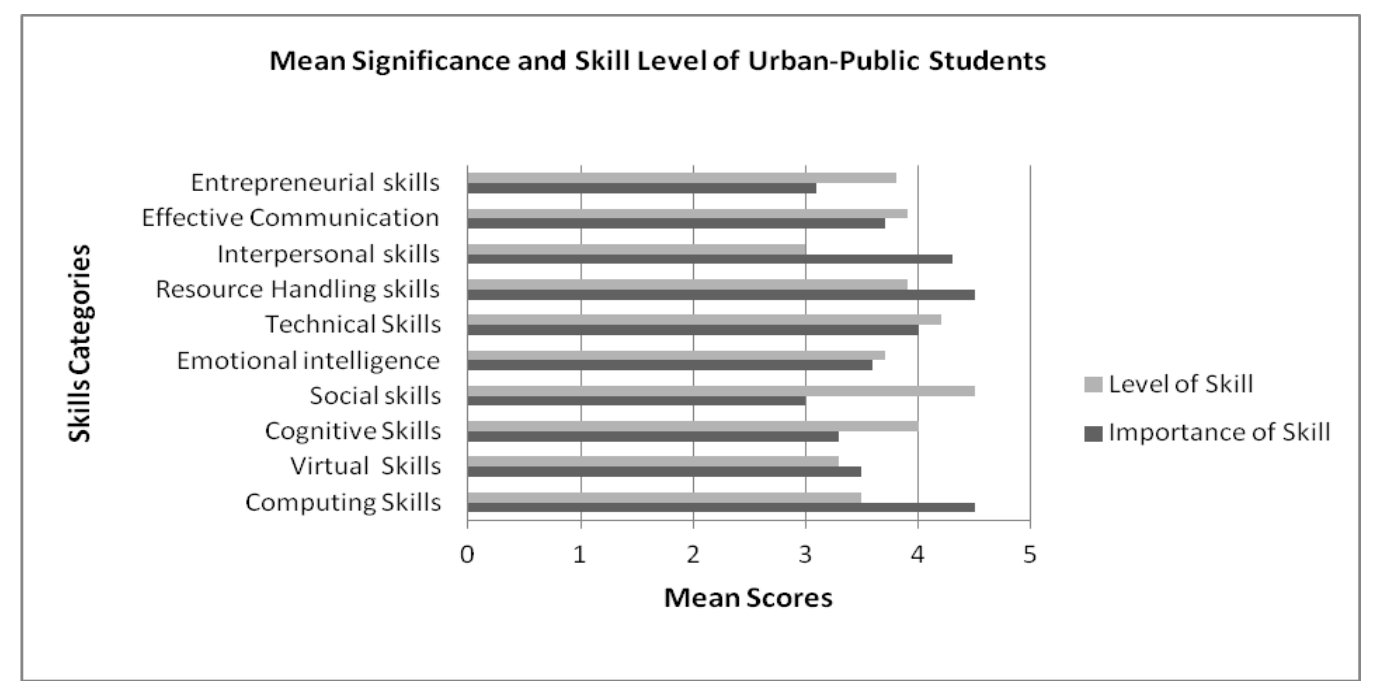

Figure 2. Mean scores of urban/public vocational students' perception.

\subsection{Independent $t$-Test Analysis of Urban/Private and Urban/Public Vocational Students Regarding Significance Level Pereception Gaps}

The known formula of the independent samples $t$-test is:

$$
t=\frac{E(X 1)-E(X 2)}{\sqrt{\frac{\left(n_{1}-1\right) \sigma_{1}{ }^{2}+\left(n_{2}-1\right) \sigma_{2}{ }^{2}}{\left(n_{1}+n_{2}-2\right)}} x \sqrt{\frac{1}{n_{1}}+\frac{1}{n_{2}}}}
$$

where $X 1$ and $X 2$ are the means of the two samples (urban/private and urban/public), $\sigma_{1}$ and $\sigma_{2}$ are the standard deviations of these two samples, and $n_{1}$ and $n_{2}$ are the numbers of observations of the two samples. The following results have been obtained for the significance of the perception gaps between these two groups of vocational students regarding significance levels (competency level results are similar but, for space-restriction reasons, we do not include them in the presentation herein). Table 3 indicates $t$-test results for the hypothesis and shows the significance of the difference of the means for the urban/private and urban/public groups about perceived importance of employability skills.

\subsection{Significance and Competency Levels of Rural/Private Vocational Students}

Figure 3 depicts the mean scores of those students who live in the rural areas and study in the private vocational institutions. The results indicate that the students give maximum importance to their technical and computing skills for early employment; however, their own competency levels in these skills are low. On the other hand, they consider that their communication and social skills are very good, but they perceive these skills as less important for procuring them jobs. The findings are further supported by Riemer, who highlights the role of communication skills as a key player in defining a robust and sustainable career for 21st century engineering graduates [43].

\subsection{Significance and Competency Level of Rural/Public Vocational Students}

Figure 4 shows the mean scores of those students who live in the rural areas and study in the public sector vocational institutes. Most of these students perceive that their technical and resource-handling skills are paramount for employment; however, they score very low in their competency levels for these two skills. Moreover, they consider themselves good in their entrepreneurial and cognitive skills, giving them more importance for employment. 


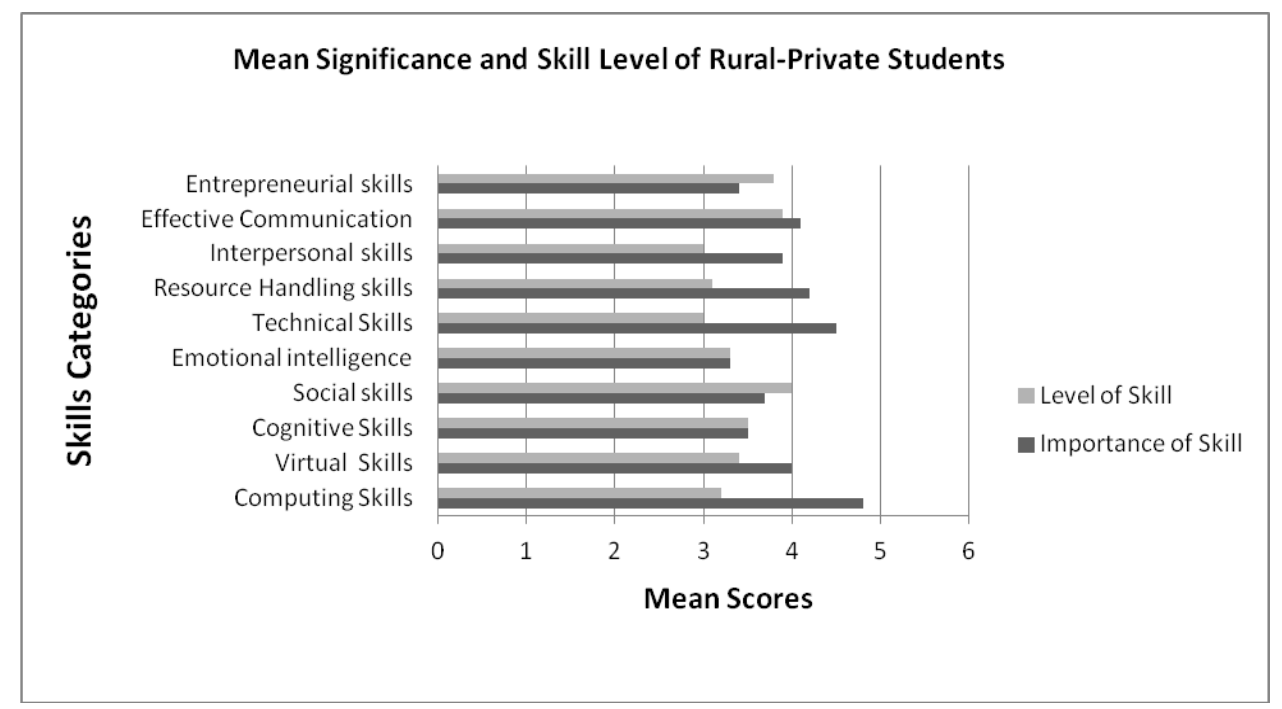

Figure 3. Mean scores of rural/private vocational students' perception.

Table 3. Hypothesis-testing $t$-test results for the statistical significance of the difference of the means for the urban/private and urban/public groups about perceived importance of employability skills.

\begin{tabular}{|c|c|}
\hline Skills Categories & $\begin{array}{c}\text { Independent Samples } t \text {-Test Results for the Significance of Difference between Means of } \\
\text { Urban/Private and Urban/Public Groups for Importance of Skills }\end{array}$ \\
\hline Computing Skills & $\begin{array}{c}\text { Extremely significant difference. } \\
p \text { value and statistical significance: The two-tailed } p \text { value is less than } 0.0001 \text {, confidence interval: } \\
\text { the mean of Group One minus Group Two equals }-0.5000,95 \% \text { confidence interval of this } \\
\text { difference: from }-0.6341 \text { to }-0.3659 \text {, intermediate values used in calculations: } \mathrm{t}=7.3326, \mathrm{df}=362 \text {, } \\
\text { standard error of difference }=0.068\end{array}$ \\
\hline Virtual Skills & Insignificant difference \\
\hline Cognitive Skills & $\begin{array}{l}\text { Extremely significant difference } \\
p \text { value and statistical significance: The two-tailed } p \text { value equals } 0.0008 \text {, confidence interval: the } \\
\text { mean of Group One minus Group Two equals }-0.3000,95 \% \text { confidence interval of this difference: } \\
\text { from }-0.4754 \text { to }-0.1246 \text {, intermediate values used in calculations: } \mathrm{t}=3.3644, \mathrm{df}=362 \text {, standard } \\
\text { error of difference }=0.089\end{array}$ \\
\hline Social Skills & $\begin{array}{c}\text { Extremely significant difference } \\
p \text { value and statistical significance: The two-tailed } p \text { value is less than } 0.0001 \text {, confidence interval: } \\
\text { the mean of Group One minus Group Two equals } 1.0000,95 \% \text { confidence interval of this } \\
\text { difference: from } 0.8370 \text { to } 1.1630 \text {, intermediate values used in calculations: } t=12.0662, \mathrm{df}=362, \\
\text { standard error of difference }=0.083\end{array}$ \\
\hline Emotional Intelligence & Insignificant difference \\
\hline Technical Skills & $\begin{array}{l}\text { Extremely significant difference } \\
\text { m value and statistical significance: The two-tailed } p \text { value equals } 0.0005 \text {, confidence interval: the } \\
\text { mean of Group One minus Group Two equals } 0.3000,95 \% \text { confidence interval of this difference: } \\
\text { from } 0.1308 \text { to } 0.4692 \text {, intermediate values used in calculations: } \mathrm{t}=3.4874, \mathrm{df}=362 \text {, standard error } \\
\text { of difference }=0.086\end{array}$ \\
\hline Resource-Handling Skills & Insignificant difference \\
\hline Interpersonal skills & $\begin{array}{l}\text { Extremely significant difference } \\
p \text { value and statistical significance: The two-tailed } p \text { value is less than } 0.0001 \text {, confidence interval: } \\
\text { the mean of Group One minus Group Two equals }-1.3000,95 \% \text { confidence interval of this } \\
\text { difference: from }-1.3970 \text { to }-1.2030 \text {, intermediate values used in calculations: } t=26.3660 \text {, } \\
\qquad \mathrm{df}=362 \text {, standard error of difference }=0.049\end{array}$ \\
\hline
\end{tabular}


Table 3. Cont.

\section{Skills Categories}

Effective Communication

Independent Samples $t$-Test Results for the Significance of Difference between Means of Urban/Private and Urban/Public Groups for Importance of Skills

Extremely significant difference

$p$ value and statistical significance: The two-tailed $p$ value is less than 0.0001 , confidence interval: the mean of Group One minus Group Two equals $-0.6000,95 \%$ confidence interval of this difference: from -0.7073 to -0.4927 , intermediate values used in calculations: $t=10.9988$, $\mathrm{df}=362$, standard error of difference $=0.055$

Extremely significant difference

$p$ value and statistical significance: The two-tailed $p$ value is less than 0.0001 , Confidence interval: the mean of Group One minus Group Two equals $0.3000,95 \%$ confidence interval of this difference: From 0.1783 to 0.4217 , Intermediate values used in calculations: $t=4.8469$, $\mathrm{df}=362$, standard error of difference $=0.062$

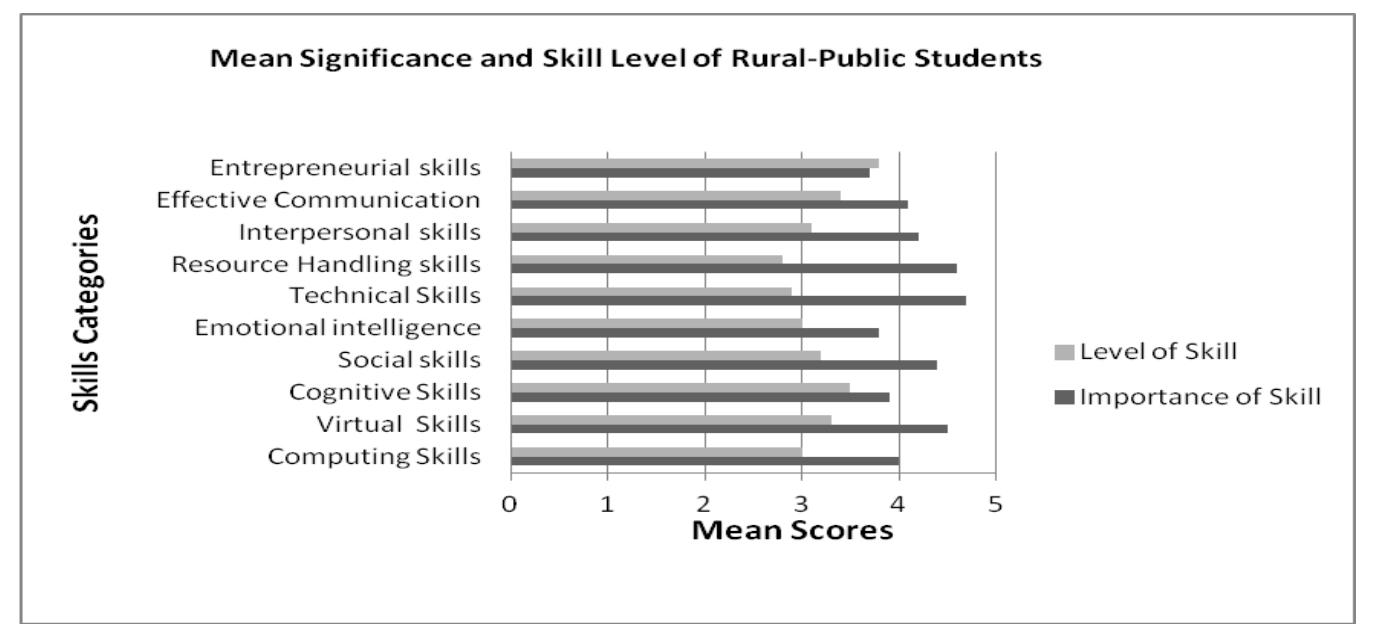

Figure 4. Mean scores of rural/public vocational students' perception.

4.6. Independent t-Test Analysis of Rural/Private and Rural/Public Vocational Students Regarding the Significance Level of Perception Gaps

On the basis of the same analysis and the calculation formula of Section 4.3 , the following results have been obtained for the significance of the perception gaps between the two groups of rural/private and rural/public vocational students regarding significance levels (competency levels results are similar and, for space-restriction reasons, we do not include them in the presentation herein). Table 4 presents the results of hypothesis testing, which indicates the difference of means for the each cluster.

Table 4. Hypothesis testing $t$-test results for the statistical significance of the difference of the means for the rural/private and rural/public groups about perceived importance of employability skills.

Skills Categories
Independent Samples $t$-Test Results for the Significance of Difference between Means of Rural/Private and Rural/Public Groups for Importance of Skills

Extremely significant difference

$p$ value and statistical significance: The two-tailed $p$ value is less than 0.0001 , confidence interval: the mean of Group One minus Group Two equals 0.8000, 95\% confidence interval of this difference: from 0.6558 to 0.9442 , intermediate values used in calculations: $t=10.9169, \mathrm{df}=317$, standard error of difference $=0.073$

Virtual Skills

Extremely significant difference

$p$ value and statistical significance: The two-tailed $p$ value is less than 0.0001 , confidence interval: the mean of Group One minus Group Two equals $-0.5000,95 \%$ confidence interval of this difference: from -0.6686 to -0.3314 , intermediate values used in calculations: $t=5.8355, \mathrm{df}=317$, standard error of difference $=0.086$ 
Table 4. Cont.

\section{Skills Categories}

Independent Samples $t$-Test Results for the Significance of Difference between Means of Rural/Private and Rural/Public Groups for Importance of Skills

Extremely significant difference

$p$ value and statistical significance: The two-tailed $p$ value is less than 0.0001 , confidence interval: the mean of Group One minus Group Two equals $-0.4000,95 \%$ confidence interval of this difference: from -0.5885 to -0.2115 , intermediate values used in calculations: $\mathrm{t}=4.1741, \mathrm{df}=317$, standard error of difference $=0.096$

\section{Extremely significant difference}

Social Skills

$p$ value and statistical significance: The two-tailed $p$ value is less than 0.0001 , confidence interval: the mean of Group One minus Group Two equals $-0.7000,95 \%$ confidence interval of this difference: from -0.8619 to -0.5381 , intermediate values used in calculations: $t=8.5055, \mathrm{df}=317$, standard error of difference $=0.082$

\section{Extremely significant difference}

Emotional Intelligence

$p$ value and statistical significance: The two-tailed $p$ value is less than 0.0001 , confidence interval: the mean of Group One minus Group Two equals $-0.5000,95 \%$ confidence interval of this difference: from -0.6531 to -0.3469 , intermediate values used in calculations: $t=6.4275, \mathrm{df}=317$, standard error of difference $=0.078$

Extremely significant difference

Technical Skills

$p$ value and statistical significance: The two-tailed $p$ value equals 0.0313 , confidence interval: the mean of Group One minus Group Two equals -0.2000 , 95\% confidence interval of this difference: from -0.3819 to -0.0181 , intermediate values used in calculations: $\mathrm{t}=2.1634, \mathrm{df}=317$, standard error of difference $=0.092$

Extremely significant difference

Resource-Handling skills

$p$ value and statistical significance: The two-tailed $p$ value is less than 0.0001 , confidence interval: the mean of Group One minus Group Two equals $-0.4000,95 \%$ confidence interval of this difference: from -0.5819 to -0.2181 , intermediate values used in calculations: $t=4.3268, \mathrm{df}=317$, standard error of difference $=0.092$

Extremely significant difference

$p$ value and statistical significance: The two-tailed $p$ value is less than 0.0001 , confidence interval: the mean of Group One minus Group Two equals $-0.3000,95 \%$ confidence interval of this

Interpersonal Skills

difference: from -0.4043 to -0.1957 , intermediate values used in calculations: $t=5.6617, \mathrm{df}=317$, standard error of difference $=0.053$

Effective Communication

Insignificant difference

Extremely significant difference

Entrepreneurial Skills

$p$ value and statistical significance: The two-tailed $p$ value is less than 0.0001 , confidence interval: the mean of Group One minus Group Two equals $-0.3000,95 \%$ confidence interval of this difference: from -0.4309 to -0.1691 , intermediate values used in calculations: $t=4.5102, \mathrm{df}=317$, standard error of difference $=0.067$

\subsection{Vocational Employers' Perception of Employability Skills}

Table 5 shows the perception level of vocational employers with regard to the importance of employability skills. It is evident from the table that employers place maximum importance on entrepreneurial, interpersonal, resource-handling, and emotional intelligence skills, followed by technical and virtual skills. On the other hand, they are found to place minimum importance on the computing and cognitive skills of students when selecting them for jobs.

\subsection{Comparison of Students' and Employers' Perception}

Figure 5 shows the perception gap between vocational students and vocational employers with regard to the importance of skills. It is clear that the maximum gap exists between interpersonal and emotional intelligence and virtual skills, while the minimum gap exists between social, technical, and resource-handling skills. However, a significant perception gap also exists between entrepreneurial, computing, and cognitive skills. 
Table 5. Perceived importance of employers with regard to employability skills.

\begin{tabular}{cccc}
\hline Vocational Employers' Employability Skills & Mean & SD & Importance \\
\hline Computing Skills & 1.43 & 0.82 & 2 \\
Virtual Skills & 2.82 & 0.69 & 5 \\
Cognitive Skills & 1.38 & 0.47 & 1 \\
Social skills & 1.43 & 0.82 & 3 \\
Emotional intelligence & 3.49 & 0.85 & 7 \\
Technical Skills & 3.41 & 0.52 & 6 \\
Resource Handlin skills & 3.82 & 0.65 & 8 \\
Interpersonal skills & 4.53 & 0.59 & 9 \\
Effective Communication & 2.45 & 0.73 & 4 \\
Entrepreneurial skills & 4.67 & 0.76 & 10 \\
\hline
\end{tabular}

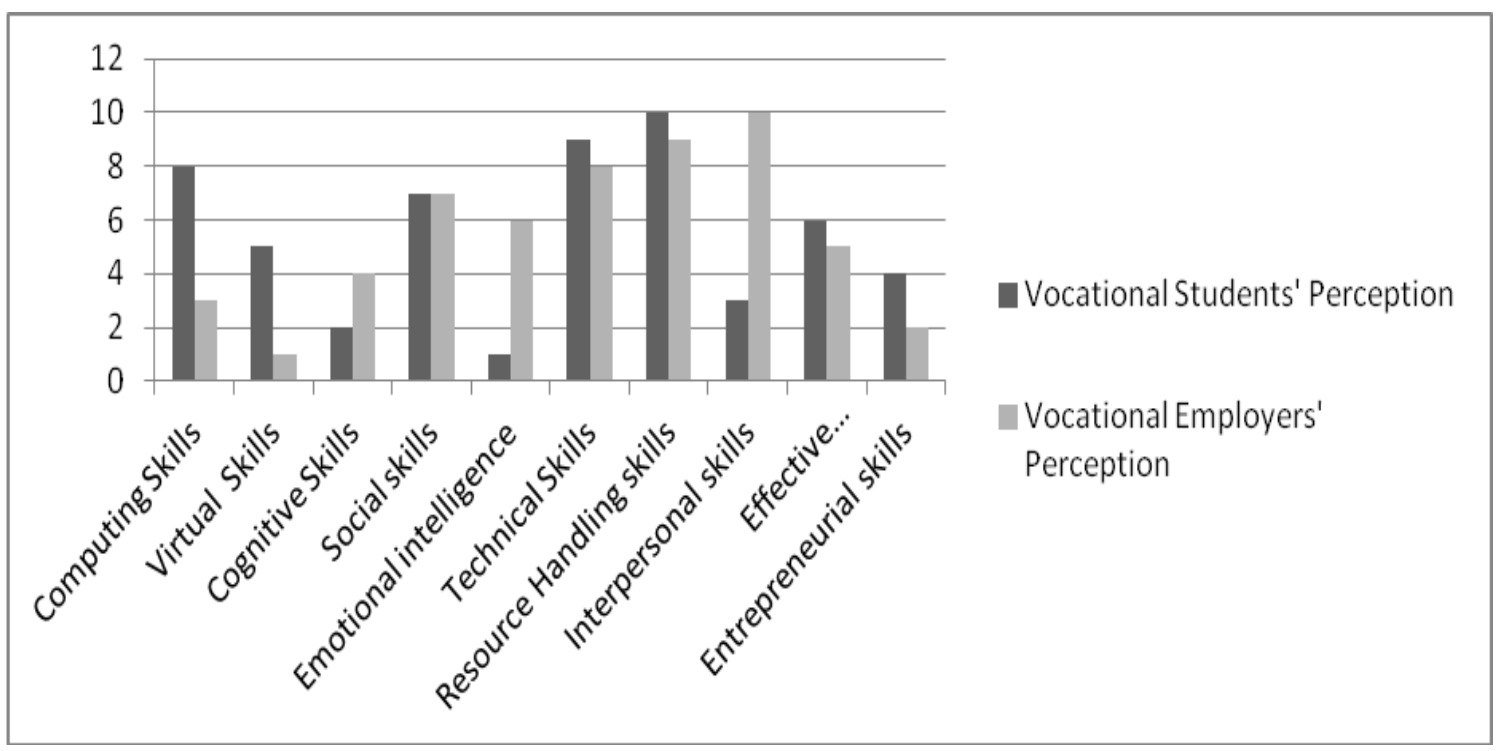

Figure 5. Comparison of vocational students and employers' perception about employability skills.

On the basis of the same analysis and the calculation formula of Sections 4.3 and 4.6, the following results have been obtained for the significance of perception gaps between the two groups of employers and vocational students regarding significance levels. Table 6 shows $t$-test results for the vocational students and employers about the perceived importance of employability skills.

\subsection{Hierarchical Analysis of the Students' Skill Levels}

Figure 6 indicates the skill levels of students in each of the four clusters of urban/private, urban/public, rural/private, and rural/public students. It is observed that urban/private students showed low levels of competency in social (3) and intrapersonal skills (3.1). Similarly, vocational students studying in public vocational institutes, but living in urban vicinities, expressed their partial low competency levels in interpersonal skills (3), virtual skills (3.3), and computing skills (3.5). Likewise, rural/private students showed low levels of competency in interpersonal skills (3), resource-handling skills (3.1), and computing skills (3.2). However, extremely low levels are witnessed in rural/public vocational students in resource-handling skills (2.8), technical skills (2.9), computing skills (3), and interpersonal skills (3.1). The results of the hierarchical analysis are further supported by the work of Triyono et al., which identified that the socioeconomic backgrounds of vocational students not only affected their competency levels, but also created a significant difference towards sustainable careers [44]. 
Table 6. Hypothesis testing $t$-test results for the statistical significance of the difference of the means for the vocational students and employers with regard to the perceived importance of employability skills.

Skills Categories $\quad$ Independent Samples $t$-Test Results for the Significance of Difference between Means of
Vocational Students and Employers Groups for Importance of Skills

Extremely significant difference

$p$ value and statistical significance: The two-tailed $p$ value is less than 0.0001 , confidence interval: the mean of Group One minus Group Two equals 5.0000, 95\% confidence interval of this difference: from 4.8507 to 5.1493 , intermediate values used in calculations: $t=65.8178, \mathrm{df}=763$, standard error of difference $=0.076$

Extremely significant difference

$p$ value and statistical significance: The two-tailed $p$ value is less than 0.0001 , confidence interval: the mean of Group One minus Group Two equals 4.0000, 95\% confidence interval of this difference: from 3.8255 to 4.1745 , intermediate values used in calculations: $\mathrm{t}=45.0332, \mathrm{df}=763$, standard error of difference $=0.089$

Extremely significant difference

Cognitive Skills $\quad p$ value and statistical significance: The two-tailed $p$ value is less than 0.0001 , confidence interval: the mean of Group One minus Group Two equals $-2.0000,95 \%$ confidence interval of this difference: from -2.1952 to -1.8048 , intermediate values used in calculations: $t=20.1325$, $\mathrm{df}=763$, standard error of difference $=0.099$

Social Skills

Emotional Intelligence

Technical Skills

Resource-Handling Skills

Effective Communication

Entrepreneurial Skills

\section{Insignificant difference}

\section{Extremely significant difference}

$p$ value and statistical significance: The two-tailed $p$ value is less than 0.0001 , confidence interval: the mean of Group One minus Group Two equals $-4.0000,95 \%$ confidence interval of this difference: from -4.1584 to -3.8416 , intermediate values used in calculations: $t=49.6018$, $\mathrm{df}=763$, standard error of difference $=0.081$

Extremely significant difference

$p$ value and statistical significance: The two-tailed $p$ value is less than 0.0001 , confidence interval: the mean of Group One minus Group Two equals 1.0000, 95\% confidence interval of this difference: from 0.8117 to 1.1883 , intermediate values used in calculations: $t=10.4345, \mathrm{df}=763$, standard error of difference $=0.096$

Extremely significant difference

$p$ value and statistical significance: The two-tailed $p$ value is less than 0.0001 , confidence interval: the mean of Group One minus Group Two equals 1.0000, 95\% confidence interval of this difference: from 0.8117 to 1.1883 , intermediate values used in calculations: $t=10.4345, \mathrm{df}=763$, standard error of difference $=0.096$

Extremely significant difference

$p$ value and statistical significance: The two-tailed $p$ value is less than 0.0001 , confidence interval: the mean of Group One minus Group Two equals $-7.0000,95 \%$ confidence interval of this difference: from -7.1079 to -6.8921 , intermediate values used in calculations: $t=127.4344$, $\mathrm{df}=763$, standard error of difference $=0.055$

Extremely significant difference

$p$ value and statistical significance: The two-tailed $p$ value is less than 0.0001 , confidence interval: the mean of Group One minus Group Two equals 1.0000, 95\% confidence interval of this difference: from 0.8806 to 1.1194 , intermediate values used in calculations: $\mathrm{t}=16.4544, \mathrm{df}=763$, standard error of difference $=0.061$

Extremely significant difference

$p$ value and statistical significance: The two-tailed $p$ value is less than 0.0001 , confidence interval: the mean of Group One minus Group Two equals 2.0000, 95\% confidence interval of this difference: from 1.8645 to 2.1355 , intermediate values used in calculations: $t=29.0044, \mathrm{df}=763$, standard error of difference $=0.069$ 


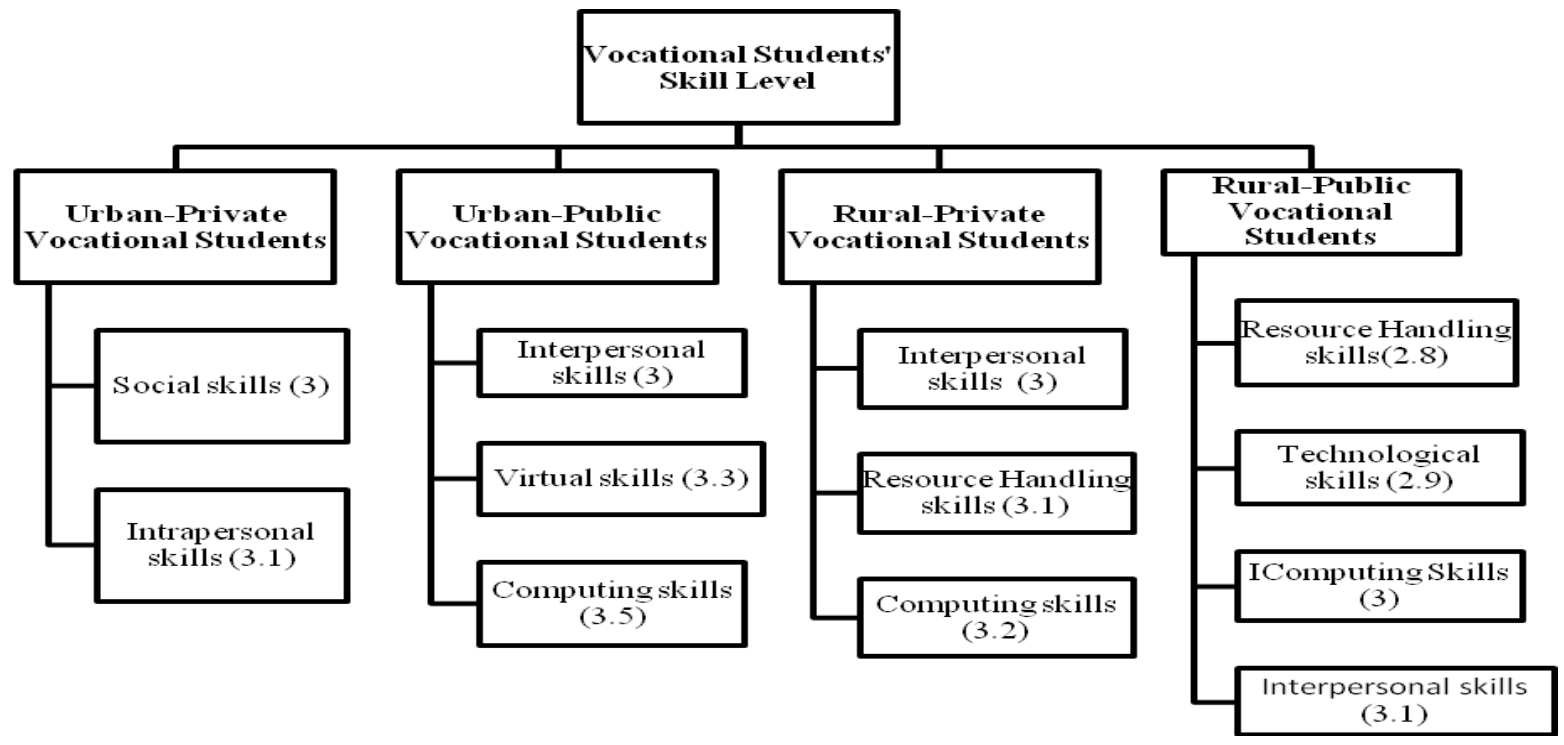

Figure 6. Hierarchical analysis of the students' skill levels.

\subsection{Mean Competency Levels of the Four Vocational Groups}

Figure 7 indicates the interval plot of the student's mean competency levels. It is evident that the students living in urban areas and studying in private institutes have expressed the highest levels of competency scores in the cluster of these skills (83.2\%), whereas the competency score of the urban/public students has shown a sharp decline $(70 \%)$. On the other hand, the students who live in the rural areas, but study in the private vocational institutes, scored $61.9 \%$ in the skills competency. However, the students belonging to rural areas and studying in the public vocational institutes scored low, showing the lowest levels of competency in these skills, which is recorded as merely $40.4 \%$. These results are in accordance with the study conducted by Andrew and Hingson that revealed the importance of alignment between soft and technical skills for progressive and sustainable advancements in their initial careers [45].

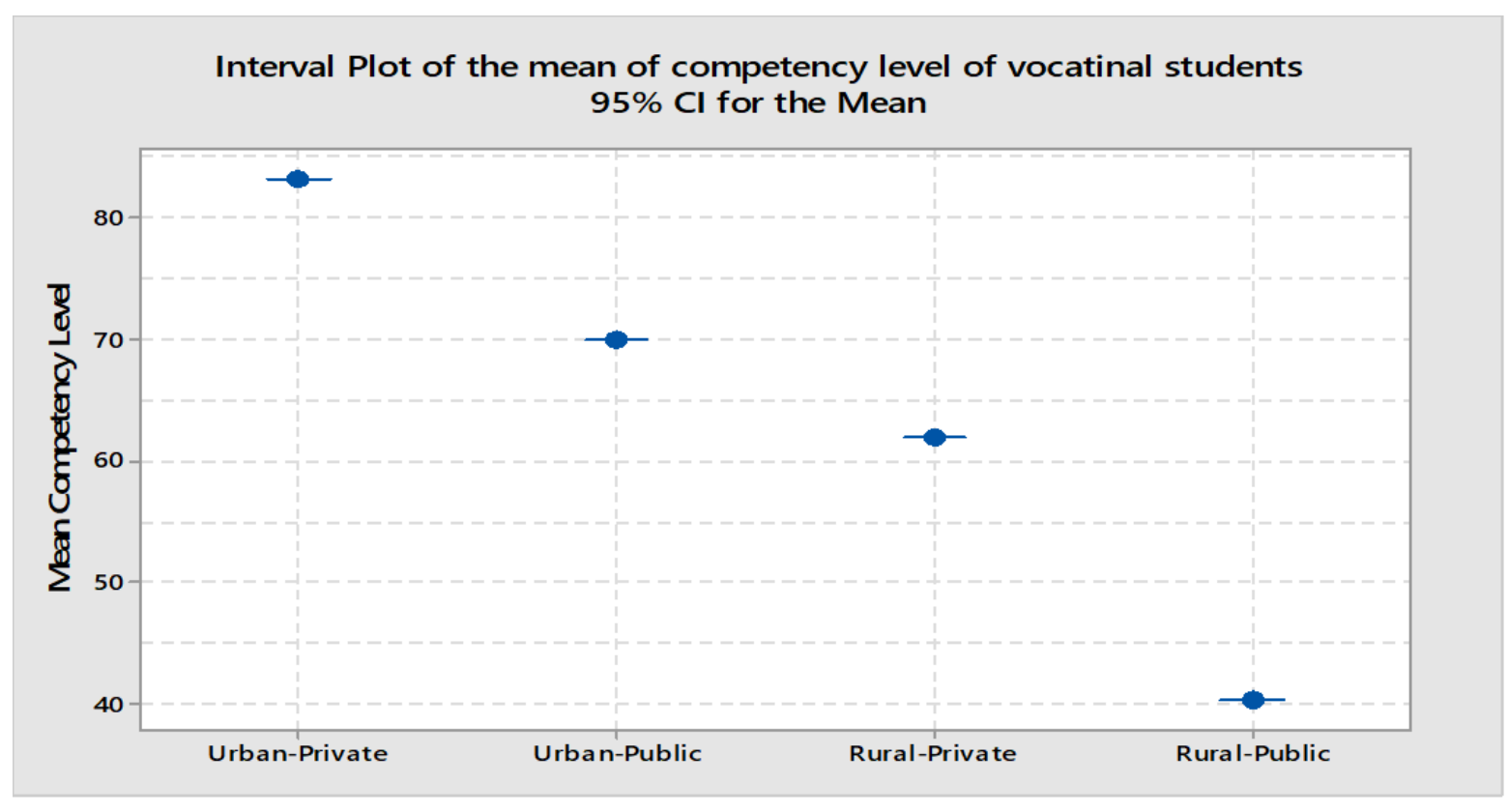

Figure 7. Interval plot of the four cluster means showing vocational students' competency. 


\subsection{Cause and Effect Relation of Vocational Students Competency Level}

Figure 8 shows the cause-and-effect analysis of the perceptions of vocational students, and their competency levels for sustainable career adaptability, with the help of the Ishikawa diagram. As is evident, the four effects of central services, teaching methodology, resource planning, and career development on vocational students are linked with the ten causes. The figure shows that the vocational institutions' central services and teaching methodologies can play dominant roles in the career adaptability of vocational students as compared to resource planning and the students' career development.

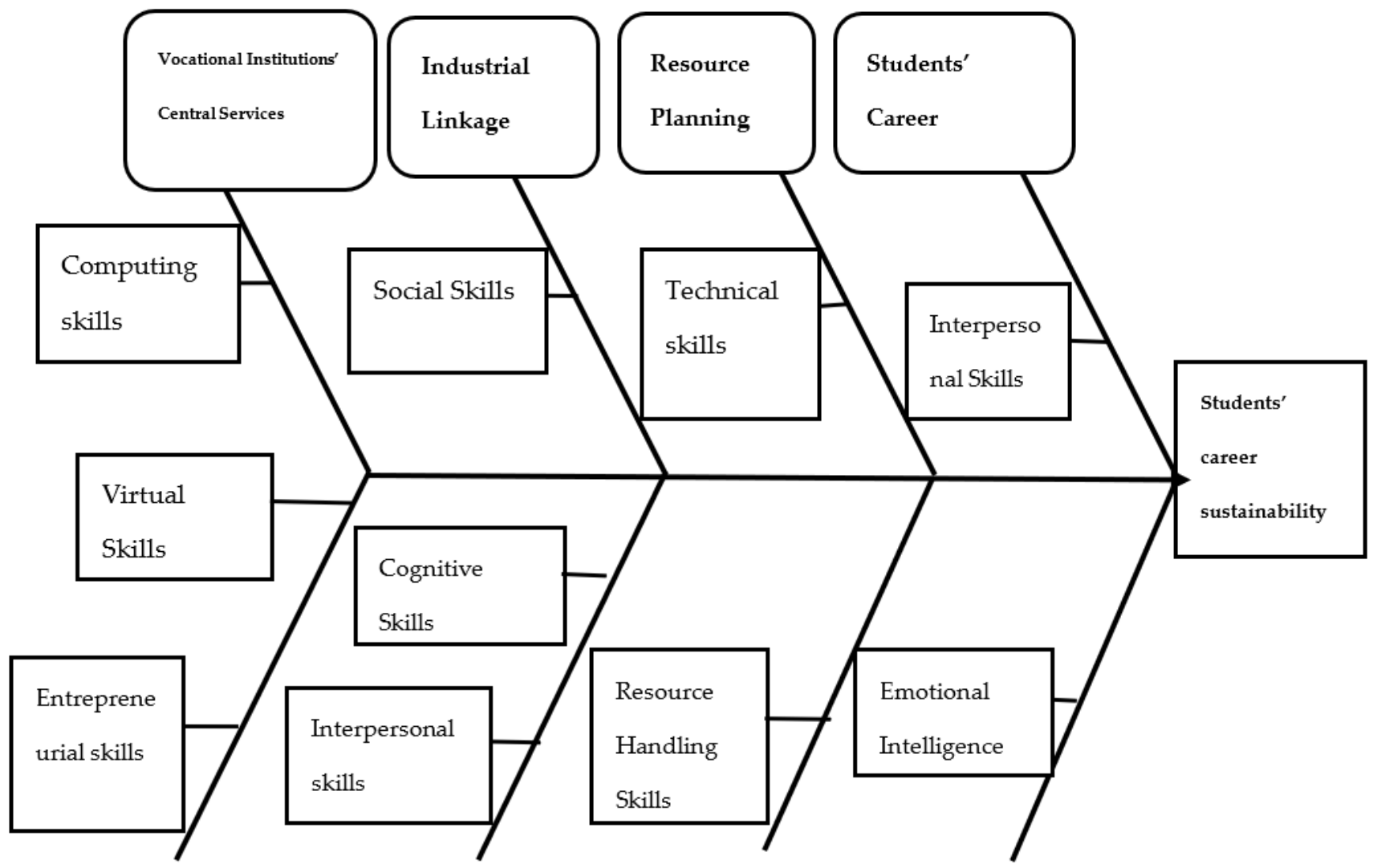

Figure 8. Ishikawa diagram showing cause and effect of student skills and competency levels.

The results of the current study have similarities with previous research, as mentioned with each category. The results reveal a significant gap between the perception level of vocational employers and vocational students with regard to employability skills. TLT and the Crites' model also emphasize the roles of the individual and each skill in order to disentangle an age effect from a cohort effect. The differences in the mean scores and percentiles of each category signify the importance of each skill for each group. Furthermore, a hierarchical analysis of the vocational students' skills states that urban/private students showed high levels of competency in social (3) and interpersonal skills (3.1), while $\mathrm{rural} /$ public students showed low levels of competency in interpersonal skills (3), resourcehandling skills (3.1), and computing skills (3.2). Furthermore, the students belonging to rural areas and studying in the public vocational institutes have shown minimum progress, which is recorded as merely $40.4 \%$. These findings are also relevant for policy focused on vocational education. The current findings indicate the significant heterogeneity of the content and hands-on practice of vocational institutions and the perception of employers with regard to these vocational skills when looking for the career optimization of these vocational students. It is vital to look for each category, venue-oriented classification, and the mean value of each skill in all categories in order to bridge the gap between vocational students and industrial demands for a sustainable future. 


\section{Remedial Framework for the Sustainability of Vocational Students}

Afterwards, the structured interviews were conducted with relevant stakeholders to figure out remedial solutions. Furthermore, the literature was also consulted in order to explore an applicable framework for the sustainability and career growth of vocational students. Finally, all of the information was synthesized in order to propose a ten-point sustainable framework reducing the perception gap and enhancing the employability chances of vocational students. This framework of possible remedial strategies is preliminarily outlined briefly below, but it is the goal of a subsequent paper by the authors to completely analyze it, and measure its impact, in order to close the perception gaps regarding employability skills between the different herein-involved bodies.

\subsection{Industry Academia Linkage (IAL)}

It is observed that there is a lack of industrial linkage between the skills learned in vocational institutions and those that are applied in industries. Therefore, a strong connection between the needed and developed skills should be planned in order to ensure sustainable careers for students, as a large number of them are unemployed, even after the completion of vocational training.

\subsection{Robust Accreditation System (RAS)}

It was observed during the structured interviews that vocational students belonging to private institutions of both urban and rural areas face accreditation issues as well. In the absence of strong accreditation mechanisms, most of the polytechnic institutes are either not accredited, or their programs are not recognized by the vocational employers. It is important that a robust accreditation system be introduced for the uniform recognition of these vocational institutes in order to bring sustainability in the carriers of vocational graduates.

\subsection{Flexibility of Curriculum (FoC)}

It is observed that the perception gap between employers and students can be reduced by making the necessary changes to the curriculum. However, in the absence of needed flexibility, it is difficult to carry out the required changes in the course curriculum. Keeping in mind the fast-changing demands of vocational employers, it is paramount that the polytechnic institutes mold their curriculums with the required pace and flexibility.

\subsection{Enhanced Social Recognition (ESR)}

Social recognition is also detected as one of the major causes of the low levels of competency in vocational students as they did not feel socially recognized. It was observed during the interviews with stakeholders that the parents of the students feel dissatisfied with the social status of the vocational graduates and, therefore, discourage their children to join vocational institutes. This problem is more rampant in the rural areas of the country. Therefore, it is important that the government should not only promote vocational education, but also ensure the necessary social recognition of these graduates for sustainability and growth.

\subsection{Supply Demand Matching (SDM)}

It is evident that a mismatch exists between the skills of vocational students and the demands of the industry. Furthermore, the students of the rural areas face problems due to lack of resources, experience, and the nonavailability of technical training. Neither are they aware of the demands of future employers or skillful enough to furnish those demands. As a result, the employability chances and the social recognition of vocational graduates become severely compromised. Therefore, a strong match must be established between the supply and demand of vocational graduates for the sustainable future of these students. 


\subsection{Flexibility of Course Design (FCD)}

Because of the weak persistency of vocational students to respond to the nonapplicable course design, vocational students face great difficulty in absorbing this content. Nevertheless, vocational institutions have introduced a hybrid type of course, but it is still not flexible enough to cater to the changing industrial requirements. Unless the contents of these courses become more in line with the requirements of employers, it will be difficult to ensure smooth and sustainable careers for vocational students.

\subsection{Distance Learning Vocational Program (DLVP)}

The fast-changing demands in employability skills have made it difficult for vocational institutions to offer these skills in both urban and rural areas of the country. Consequently, the students of the rural areas, in particular, face a major mismatch in their employability skills. The phenomenon not only produces stress and anxiety, but also results in increased unemployment among the already poor populace of rural areas. It is necessary to introduce distance learning vocational programs (DLVP) in order to fill the gap and ensure the sustainable careers for rural-area youth as well.

\subsection{Career Planning \& Guidance (CPG)}

In the absence of sound career planning and guidance, students are neither aware of the changing labor market nor of the incoming opportunities. Most of the time, they choose a career that is not related to their skills or aptitudes. In turn, they do not achieve any sustainability and continue to change careers without any aim or objective. Under these situations, students must be provided with both career planning and guidance for the selection of the right track at different stages of their careers.

\subsection{Teacher Training Programs (TTPs)}

In the absence of regular refresher courses for teacher training (TTs), it is difficult to update their knowledge and skills. Reciprocally, the students also receive outdated and obsolete knowledge. This phenomenon produces graduates that are not the first choice of future employers. It is mandatory that regular training programs be conducted in order to update the existing knowledge levels of teachers and to make them capable enough to impart the most relevant skills and knowledge to their students. It could provide an outlet for a sustainable future that would also lead vocational students towards a successful future.

\subsection{National Skill Strategy (NSS)}

A significant difference is observed with regard to employability skills between the perception of urban and rural area students. Not only are the students confused about their employability time after graduation, but the vocational employers are also not clear with regard to the skill levels of these graduates. Under these circumstances, it is vital that a national skill strategy be developed that works as a guideline for all stakeholders. The government should eliminate the rural/urban difference by consultation with all stakeholders for the sustainable future of the youth.

\section{Discussion}

Previous studies on employability skills have mostly focused on the behaviors and skills of students in connection with the employability rate [46,47]. However, the findings of the current study amalgamate the input of industrial employers as well and conclude that vocational students, belonging to four clusters, follow an asymmetrical pattern in both ranking and competency due to differences in their perceptions. Similarly, a significant perception gap was also found between vocational employers and students. Vocational employers place maximum importance on interpersonal, technical, and entrepreneurial skills, while students perceive that their technical and computing skills are vital for sustainable careers. Similarly, the rural/public students show minimum levels of competency 
in these skills as compared to their counterparts living in rural areas and studying in the private institutions. On the other hand, vocational students living in urban vicinities and studying in private vocational institutions felt more confident as compared with their contemporaries studying in the public sector institutions and living in the rural areas of the country. The private vocational institutes not only arrange more industrial trips for their students, but also encourage them to get some hands-on experience before formally joining these organizations. This liaison helps these students to gain firsthand experience of real working environments and allows them to stay in touch with these employers for future employment. Furthermore, their competency levels in these skills also improves because of more awareness with regard to the utility of these skills in problem solving and decision making. However, on the other hand, these students show low levels of competency in their communication and virtual skills. It is mainly because of more time spent focusing on the technical and other hardcore skills related to their specialties. Similarly, students from the urban/public cluster show low levels of competency in interpersonal skills and virtual skills, due to more emphasis being placed on technical skills by their institutions. Because of the nonflexibility in curriculums, most of the public sector institutions focus on covering the curriculum and pay less attention to the students' personal growth and career development. Similarly, students from the rural/private cluster are extremely dissatisfied with the nonavailability of resources that are mandatory for the development of skills, as they have shown the lowest skill levels at $40.4 \%$. Their low levels of competency can be seen in every skill except entrepreneurial skills. They feel very disappointed in the absence of any personal or professional development, and their employability chances are severely compromised. Furthermore, because of little to no linkage with local vocational employers, a wide perception gap exists between students and vocational employers with regard to employability skills.

Consequently, educational leaders should consider the dynamics of changing market needs and incorporate them into their curriculum, in addition to adding in-demand handson activities to cater to the requirements of vocational employers [48]. In light of the results, it is evident that a significant perception gap exists between vocational employers and vocational students with regard to the importance of employability skills, which is tantamount to validating the first research hypothesis. The results further indicate that students living in rural areas give more importance to their technical and computing skills, which is in sharp contrast to their contemporaries in urban areas, who place more importance on their resource-handling skills. Therefore, it is evident that the second research hypothesis is also valid, which states that living in urban/rural areas creates a significant difference with regard to the perception of employability skills. Moreover, the third hypothesis is also found to be valid, which states that studying in public or private vocational institutions creates a significant difference in the competency levels of employable skills. In the cases of both urban- and rural-area students, the results indicate that the students who study in private vocational institutes feel more confident in their skill competencies as compared to their contemporaries studying in public sector institutes.

Keeping in mind that a sustainable career hinges on the perception of both students and employers with regard to employability skills, it is imperative that any mismatch between the perception of vocational students and employers with regard to employability skills should be reduced. Similarly, vocational students should improve their communication skills, in addition to working on their technical skills, for career sustainability. Likewise, the development of emotional intelligence and social skills helps them to deal with diverse situations, which significantly improves their chances of career growth $[49,50]$. The findings also reveal the significance of the interaction of vocational employers with vocational institutes, as it can help the educational leaders to improve the quality of these programs.

Eventually, after analyzing results, observations, literature review, and employers' reviews, a sustainable framework is suggested for the reduction of the perception gap. A list of skills requiring actions for improvement, along with the responsible stakeholders, is presented in Table 7. 
Table 7. A remedial table along with the list of needed actions and their sponsors.

\begin{tabular}{|c|c|c|c|}
\hline List of Skills & Required Actions & Impact of Action & Responsibility \\
\hline Computing Skills & Teachers' Training & \multirow{3}{*}{$\begin{array}{l}\text { Vocational Institutions' } \\
\text { Central Services }\end{array}$} & \multirow{3}{*}{ Government } \\
\hline Virtual Skills & $\begin{array}{c}\text { Employability Demand and Supply } \\
\text { Matching }\end{array}$ & & \\
\hline Technical Skills & Flexible Curriculum & & \\
\hline Social Skills & Social Recognition & \multirow{3}{*}{ Industrial Linkage } & \multirow{3}{*}{ Teachers } \\
\hline Emotional Intelligence & Accreditation System & & \\
\hline Cognitive Skills & Industrial Linkage & & \\
\hline Interpersonal Skills & Distance Learning Vocational Program & Resource & Government \\
\hline Resource-handling Skills & Career Guidance & Planning & Teachers \\
\hline Entrepreneurial Skills & National Skill Strategy & Students' Career & Government, Teachers \\
\hline Effective Communication & The flexibility of Course Design & Development & Students \\
\hline
\end{tabular}

The details given in Table 7 can be beneficial for vocational employers, students, teachers, and all connected stakeholders who can play a vital role with the help of this remedial framework. The table indicates the needed actions, their impact, and those responsible for taking these actions. In this regard, the role of the government and other stakeholders is also mentioned in order to secure a prosperous and sustainable future of vocational students.

\section{Conclusions}

The key focus of the study was to find the perception gap between vocational students and vocational employers with regard to employability skills. The results reveal that a significant perception gap exists between vocational students and industrial employers. The vocational students, who were further categorized into four clusters of urban/public, urban/private, rural/public, and rural/private also showed significant differences in their within-the-group perceptions, where the competency score of urban/private students is recorded as $83.2 \%$, while the competency score of urban/public students indicate a low level of $70 \%$. On the other hand, rural/private students scored $61.9 \%$, while rural/public vocational students scored the lowest at $40.4 \%$. It is observed that the vocational programs that are not properly accredited further jeopardize the effectiveness of vocational education, which is already facing issues with regard to social acceptance and recognition in the context of developing countries.

Nevertheless, polytechnic institutions are growing in number. However, in the absence of a strong linkage with vocational employers, these programs fail to get early employment for their graduates. The students of rural areas, who study in the public sector institutes, experience minimum competency levels in both technical and nontechnical skills. In today's world, where vocational training works as a major transition, joining youth with the industrial world, it is imperative that these programs be well-aligned with labor market requirements. Moreover, personal development, along with professional development, should be focused for the robust and sustainable careers of the graduating vocational students. The results of the current study can be beneficial for both educational leaders and vocational employers for enhancing the quality of these programs and ensuring sustainable careers for vocational students. Although the current results are highly significant and bring novelty to the existing literature, they also carry numerous limitations due to the impact of COVID-19 on data collection. Future research can contribute to the same area, with wider coverage around the globe, by exploring the teaching practices, sources, and outcomes for pluralistic results.

Author Contributions: Supervision, A.R., M.S. and H.A.; data collection and analysis, S.H.S. and D.A.K.; writing - original draft, A.R., H.A., D.A.K., M.S., S.H.S. and Z.A. All authors have read and agreed to the published version of the manuscript. 
Funding: This research received no external funding.

Institutional Review Board Statement: Not applicable.

Informed Consent Statement: Not applicable.

Data Availability Statement: Data will be provided on demand.

Conflicts of Interest: The authors declare no conflict of interest associated with this research article.

\section{References}

1. Nwosu, J.C.; Micah, E.M. Technical and vocational education and training as a tool for national sustainable development in Nigeria. Int. J. Soc. Sci. Humanit. Invent. 2017, 4, 3983-3988.

2. Scully-Russ, E. Human resource development and sustainability: Beyond sustainable organizations. Hum. Resour. Dev. Int. 2012, 15, 399-415. [CrossRef]

3. Gutierrez-Gutierrez, L.J.; Barrales-Molina, V.; Kaynak, H. The role of human resource-related quality management practices in new product development. Int. J. Oper. Prod. Manag. 2018, 38, 43-66. [CrossRef]

4. Moldovan, L. Sustainability assessment framework for VET organizations. Sustainability 2015, 7, 7156-7174. [CrossRef]

5. Forster, A.G.; Bol, T. Vocational education and employment over the life course using a new measure of occupational specificity. Soc. Sci. Res. 2018, 70, 176-197. [CrossRef]

6. Terentyeva, I.V.; Kirillova, O.; Kirillova, T.; Pugacheva, N.; Lunev, A.; Chemerilova, I.; Luchinina, A. Arrangement of cooperation between labour market and regional vocational education system. Int. J. Educ. Manag. 2018, 32, 1041-1055. [CrossRef]

7. Billett, S.; Choy, S.; Hodge, S. Enhancing the standing of vocational education and the occupations it serves: Australia. J. Vocat. Educ. Train. 2020, 72, 270-296. [CrossRef]

8. Alsulami, H.; Bashir, M.; Rizwan, A.; Elnahas, N.; Bawareth, F.; Noorelahi, R.; Kamrani, R. Impact of emotional intelligence on the academic performance and employability of female engineering students in Saudi Arabia. Int. J. Eng. Educ. 2019, $35,119-125$.

9. Manzoor, U.; Rizwan, A.; Demirbas, A.; Hafiz, N.A.S. Analysis of perception gap between employers and fresh engineering graduates about employability skills: A case study of Pakistan. Int. J. Eng. Educ. 2018, 34, 248-255.

10. Velde, C. Employers' perceptions of graduate competencies and future trends in higher vocational education in China. J. Vocat. Educ. Train. 2009, 61, 35-51. [CrossRef]

11. Locke, P.; Maton, K. Serving two masters: How vocational educators experience marketisation reforms. J. Vocat. Educ. Train. 2019, 71, 1-20. [CrossRef]

12. Jabarullah, N.H.; Hussain, H.I. The effectiveness of problem-based learning in technical and vocational education in Malaysia. Educ. Train. 2019, 61, 552-567. [CrossRef]

13. Deaconu, A.; Dedu, E.M.; Igreț, R.Ș.; Radu, C. The Use of Information and Communications Technology in Vocational Education and Training-Premise of Sustainability. Sustainability 2018, 10, 1466. [CrossRef]

14. Köpsén, J. Demands-based and employer-driven curricula: Defining knowledge in higher vocational education and training Stud. Contin. Educ. 2020, 42, 349-364. [CrossRef]

15. Okolie, U.C.; Nwajiuba, C.A.; Binuomote, M.O.; Ehiobuche, C.; Igu, N.C.N.; Ajoke, O.S. Career training with mentoring programs in higher education. Educ. Train. 2020, 62, 214-234. [CrossRef]

16. Wang, S.-L.; Chen, H.-P.; Hu, S.-L.; Lee, C.-D. Analyzing Student Satisfaction in the Technical and Vocational Education System through Collaborative Teaching. Sustainability 2019, 11, 4856. [CrossRef]

17. Bolli, T.; Caves, K.M.; Renold, U.; Buergi, J. Beyond employer engagement: Measuring education-employment linkage in vocational education and training programmes. J. Vocat. Educ. Train. 2018, 70, 524-563. [CrossRef]

18. Asadullah, M.A.; Ullah, A.Z. Social-economic contribution of vocational education and training: An evidence from OECD countries. Ind. Commer. Train. 2018, 50, 172-184. [CrossRef]

19. Renold, U.; Bolli, T.; Caves, K.; Bürgi, J.; Egg, M.E.; Kemper, J.; Rageth, L. Feasibility Study for a Curriculum Comparison in Vocational Education and Training. Intermediary Report II: Education-Employment Linkage Index; KOF Studien: Zurich, Switzerland, 2016.

20. Ayub, H. Parental influence and attitude of students towards technical education and vocational training. Int. J. Inf. Educ. Technol. 2017, 7, 534-538. [CrossRef]

21. Amin, M.; Tatlah, I.A.; Islam, M. Leadership Styles of the Campus Principals and Divisional Directors in a Public University of Pakistan. Bull. Educ. Res. 2018, 40, 155-181.

22. Alam, N. The role of technical vocational education and training in human development: Pakistan as a reference point. Eur. Sci. J. 2015, 11, 35-50.

23. Khilji, B.A.; Kakar, Z.K.; Subhan, S. Impact of vocational training and skill development on economic growth in Pakistan. World Appl. Sci. J. 2012, 17, 1298-1302.

24. Chamadia, S.; Mubarik, M.S. Assessing the effectiveness of vocational training programs in Pakistan: An experimental study. Educ. Train. 2021, 63, 665-678. [CrossRef]

25. Nooruddin, S. Technical and vocational education and training for economic growth in Pakistan. J. Educ. Educ. Dev. 2017, 4, 130-141. [CrossRef]

26. Mezirow, J. Transformative learning theory. In Contemporary Theories of Learning; Routledge: Oxfordshire, UK, 2018; pp. 114-128. 
27. Schnepfleitner, F.M.; Ferreira, M.P. Transformative Learning Theory-Is It Time to Add A Fourth Core Element? J. Educ. Stud. Multidiscip. Approaches 2021, 1, 40-49. [CrossRef]

28. Crites, J.O. A comprehensive model of career development in early adulthood. J. Vocat. Behav. 1976, 9, 105-118. [CrossRef]

29. Ertelt, B.; Frey, A.; Hochmuth, M.; Ruppert, J.; Seyffer, S. Apprenticeships as a Unique Shaping Field for the Development of an Individual Future-Oriented Vocationality. Sustainability 2021, 13, 2279. [CrossRef]

30. Pool, L.D.; Sewell, P. The key to employability: Developing a practical model of graduate employability. Educ. Train. 2007, 49, 277-289. [CrossRef]

31. Crossman, J.E.; Clarke, M. International experience and graduate employability: Stakeholder perceptions on the connection. High. Educ. 2010, 59, 599-613. [CrossRef]

32. Rizwan, A.; Choudhary, M.; Jahanzaib, M.; Ammar, A. Analysis of factors affecting the stress level of engineering students from remote areas. Int. J. Eng. Educ. 2013, 29, 926-932.

33. Mezirow, J. Transformative learning: Theory to practice. New Dir. Adult Contin. Educ. 1997, 1997, 5-12. [CrossRef]

34. Becker, G.S. Human Capital: A Theoretical and Empirical Analysis, with Special Reference to Education; University of Chicago Press: Chicago, IL, USA, 2009.

35. Shavit, Y.; Walter, M. From School to Work. A Comparative Study of Educational Qualifications and Occupational Destinations; Oxford University Press: Cary, NC, USA, 1998.

36. Smith, C.; Ferns, S.; Russell, L. Conceptualising and Measuring 'Employability'_Lessons from a National OLT Project. ACEN National Conference. 2014, pp. 139-148. Available online: http:/ / acen.edu.au/resources/475/ (accessed on 10 October 2021.).

37. Leveson, L. Disparities in perceptions of generic skills: Academics and employers. Ind. High. Educ. 2000, 14, 157-164. [CrossRef]

38. Sin, C.; Neave, G. Employability deconstructed: Perceptions of Bologna stakeholders. Stud. High. Educ. 2016, 41, 1447-1462. [CrossRef]

39. Van der Heijden, B.I.; Notelaers, G.; Peters, P.; Stoffers, J.M.; De Lange, A.H.; Froehlich, D.E.; Van der Heijde, C.M. Development and validation of the short-form employability five-factor instrument. J. Vocat. Behavior. 2018, 106, 236-248. [CrossRef]

40. Paadi, K.; Barkhuizen, N.; Swanepoel, S. Exploring the building blocks of an employee value proposition for graduate interns. Int. J. Soc. Sci. Humanit. Stud. 2019, 11, 51-67.

41. Bakar, A.R.; Hanafi, I. Assessing employability skills of technical-vocational students in Malaysia. J. Soc. Sci. 2007, 3, 202-207. [CrossRef]

42. Zaharim, A.; Yusoff, Y.M.; Mohamed, A.; Omar, M.Z.; Muhamad, N.; Mustapha, R. Practical framework of employability skills for engineering graduate in Malaysia. In Proceedings of the IEEE EDUCON 2010 Conference, Madrid, Spain, 14-16 April 2010; pp. 921-927.

43. Riemer, M.J. Communication skills for the 21st century engineer. Glob. J. Engng. Educ. 2007, 11, 89-100.

44. Triyono, M.B.; Trianingsih, L.; Nurhadi, D. Students' employability skills for construction drawing engineering in Indonesia. World Trans. Eng. Technol. Educ. 2018, 16, 29-35.

45. Andrews, J.; Higson, H. Graduate employability, 'soft skills' versus 'hard' business knowledge: A European study. High. Educ. Eur. 2008, 33, 411-422. [CrossRef]

46. Blázquez, M.; Herrarte, A.; Llorente-Heras, R. Competencies, occupational status, and earnings among European university graduates. Econ. Educ. Rev. 2018, 62, 16-34. [CrossRef]

47. Rizwan, A.; Alsulami, H.; Shahzad, A.; Elnahas, N.; Almalki, S.; Alshehri, R.; Alamoudi, M.; Alshoaibi, H. Perception Gap of Employability Skills between Employers' and Female Engineering Graduates in Saudi Arabia. Int. J. Eng. Educ. 2021, 37, 341-350.

48. Robinson, V.M.; Lloyd, C.A.; Rowe, K.J. The impact of leadership on student outcomes: An analysis of the differential effects of leadership types. Educ. Adm. Q. 2008, 44, 635-674. [CrossRef]

49. Pan, Y.-J.; Lee, L.-S. Academic performance and perceived employability of graduate students in business and management-an analysis of nationwide graduate destination survey. Procedia Soc. Behav. Sci. 2011, 25, 91-103. [CrossRef]

50. Fakhar, A.; Jahanzaib, M.; Sarfraz, M.H.; Shafiq, M.; Rizwan, A. Investigating the Impact of Emotional Intelligence on Academic Performance of Engineering Students: An Exploratory Study in Pakistan. Nucleus 2020, 53, 105-111. 